\title{
Finding Best PEEP: A Little at a Time
}

PEEP confers benefit by recruiting atelectatic areas for gas exchange, increasing functional residual capacity, improving compliance, and elevating arterial oxygen tension. Conversely, unnecessary PEEP may encourage overdistention of lung units that are already open, thereby reducing compliance, hyperinflating, and predisposing to alveolar disruption. Simultaneously, vascular compression by distended lung and elevated pleural pressure increases right-ventricular afterload, redistributes pulmonary blood flow, generates ventilatory dead space, and impedes venous return.

Whether a given PEEP setting improves or impairs overall lung performance depends on the relative contributions of recruitment and distention. This innate and usually unpredictable benefit/risk dichotomy has led investigators to seek a single reliable indicator of the best set point by PEEP titration. Tidal compliance, which (unlike arterial oxygenation) can be quickly, noninvasively, and repeatedly determined at the bedside, has been used for this purpose since the first days of PEEP use in ARDS. ${ }^{1}$ In the mid1970s, Suter and colleagues ${ }^{2}$ published influential data from 15 normovolemic patients receiving volume-controlled mechanical ventilation for acute respiratory failure. In that seminal report, the end-expiratory pressure resulting in maximum oxygen transport and lowest dead space fraction also yielded the highest total static compliance. Remarkably, best PEEP in this trial varied over a wide range (ie, $0-15 \mathrm{~cm} \mathrm{H}_{2} \mathrm{O}$ ). When PEEP was increased beyond its optimal level, mixed venous $\mathrm{PO}_{2}$ decreased, suggesting a reduction in $\mathrm{O}_{2}$ transport. Noting that measurement of cardiac output or a true mixed venous blood sample is frequently not available (then or now), tidal compliance was suggested as a means to indicate the level of PEEP likely to result in the best overall cardiopulmonary function. ${ }^{2}$ In volume-controlled ventilation, highest compliance is tracked faithfully by the driving pressure: $\Delta \mathrm{P}=$ [plateau pressure - PEEP]. Thus, finding the PEEP that minimizes driving pressure and maximizes tidal compliance for the tidal volume selected may simultaneously

The authors have disclosed no conflicts of interest.

Correspondence: David J Dries MSE MD, Regions Hospital, 640 Jackson Street, \#11503C, St. Paul, MN 55101. E-mail: david.j.dries@ healthpartners.com.

DOI: $10.4187 /$ respcare.07799 optimize $\mathrm{O}_{2}$ delivery and cardiac loading, which is an important and often neglected aspect of machine adjustment.

Understanding the impact of tidal volume on recruitment, the authors of that work from nearly 5 decades ago wisely noted that patients with acute respiratory failure differ and therefore should not be treated indiscriminately.

See the Original Study on Page 583

Later work from that same group confirmed that the PEEP associated with best compliance does indeed vary with tidal volume. ${ }^{3}$ The implication is that, for the same patient, multiple compliance-based optimal values of PEEP exist. In that mid- to late 1970 s era, barotrauma occurred frequently, but high tidal volumes were not otherwise of major concern; the histologic damage known as ventilator-induced lung injury (VILI) was yet to be brought to general attention. $^{4}$

The National Institutes of Health-sponsored Acute Respiratory Distress Syndrome Network trial (ARMA) that tested tidal volumes of 6 versus $12 \mathrm{~mL} / \mathrm{kg}$ predicted body weight has been widely viewed as confirming that a general strategy of using lower tidal volumes and higher frequencies reduces the mortality risk from ARDS. ${ }^{5}$ Refinement of that concept was advanced $15 \mathrm{y}$ later in a sophisticated statistical analysis of multiple high-quality trials by Amato and colleagues. ${ }^{6}$ Their influential report indicated that it was the driving pressure, not tidal volume or even plateau pressure, that was the prime culprit variable that could predict ventilator-associated mortality risk. In these trials, which used low tidal volume, improved survival was observed only when high driving pressures were avoided. That work has been widely interpreted as demonstrating that the limitation of driving pressure influences mortality, quite apart from its value as a PEEP-setting index. ${ }^{7}$

This may or may not be the case; we must remember that there is still no concrete evidence that VILI is the causal link between the ventilating prescription and mortality risk. Rather, higher driving pressures may reflect severity of underlying disease and the need to ventilate a patient with high systemic $\mathrm{O}_{2}$ demands using a baby lung of reduced capacity. ${ }^{8}$ Thus, although driving pressure is certainly a helpful clinical tool for setting PEEP and may indeed influence outcome, the true picture in any given patient is undoubtedly 
more complex. For example, pressure does not equate to tissue stretch, and driving pressure may to some extent reflect the compliance of the chest wall and positional factors. Moreover, ventilating power, of which driving pressure is but one determinant, may lie closer to the root cause of VILI than any individual pressure, volume, or flow. ${ }^{9,10}$

Putting such doubts aside, driving pressure may provide a link that helps explain why studies of higher PEEP did not show consistent survival benefit. ${ }^{11}$ PEEP increments could be protective only when increased PEEP alters lung mechanics so that the same tidal volume is delivered with lower driving pressure (ARDSnet). This interpretation is consistent with physiologic studies suggesting that the benefits of PEEP are most often found in patients with greater lung recruitability. On the other hand, ventilation with inappropriately low PEEP encourages progressive atelectasis, decreased respiratory system compliance, and, ultimately, higher driving pressure. ${ }^{12}$

In the current issue of RESPIRATORY CARE, Sahetya et $\mathrm{al}^{13}$ address the performance of the ARDSnet lower PEEP/ $/ \mathrm{F}_{\mathrm{IO}_{2}}$ table for PEEP selection among a small group of subjects with lung injury of Berlin-defined moderate to high severity. ${ }^{14}$ In each subjects, PEEP was adjusted up and down from its initial setting from the ARDSNet table, and driving pressure was measured at each PEEP level. End-expiratory pressure was then titrated to produce the lowest driving pressure, and stability at that value was confirmed over a 30-min observation period. Contrary to their anticipated results, which would have favored elevating PEEP from the tabulated baseline value, PEEP that produced the lowest driving pressure increased in some subjects and decreased in others. In fact, in some cases, the PEEP required to minimize driving pressure fell considerably below that specified by the subjectively established ARDSNet lower PEEP/ $/ \mathrm{F}_{2}$ table.

This useful work by the Johns Hopkins group invites several observations. First, the $\mathrm{PEEP} / \mathrm{F}_{\mathrm{IO}_{2}}$ table proposed by the ARDSNet investigators, which is based on $\mathrm{O}_{2}$ exchange and not mechanics, may be a reasonable start for matching PEEP to the selected tidal volume. However, as demonstrated here, we cannot rely on that arbitrarily set table to predict optimized respiratory system mechanics. As shown long ago, best PEEP depends on tidal volume and should reflect hemodynamic impact as well as VILI risk..$^{2,3}$ Not all stepwise methods of setting PEEP require a recruiting maneuver, nor are they equally helpful. ${ }^{15}$ Yet, because PEEP adjustments affect multiple important variables, whereas the strength of hypoxic pulmonary vasoconstriction varies widely among patients, careful titration to a rapidly responsive bedside indicator of mechanics (eg, driving pressure or compliance) remains the key to sorting through the complexity of the individual patient. The results from Sahetya et $\mathrm{al}^{13}$ illustrate once again that determining whether PEEP should be increased or decreased should be an empirically determined process, not a "look it up" process.
An encouraging observation from this study was the rapid response of driving pressure to stepwise PEEP titration. ${ }^{13}$ With tidal volume fixed, we must assume that the change in PEEP is entirely responsible for the ultimate optimization of respiratory mechanics and alteration of driving pressure. However, we are not informed whether patients were passively ventilated, nor whether neuromuscular blockade and proning were in play. Finally, changes in respiratory system mechanics for this patient group may not be relevant to all patients with ARDS, given that the mean body mass index of subjects studied in this trial was rather high (ie, nearly $38 \mathrm{~kg} / \mathrm{m}^{2}$ ). Chest wall and body position have the potential to affect measurements of the mechanical properties of the respiratory system that are based on airway rather than transpulmonary pressure. ${ }^{16}$

This small study by Sahetya et $\mathrm{al}^{13}$ supports the relevance of physiologic titration; as we have learned before, a standardized care guideline (or table) may be a pragmatic convenience, but its applicability to the individual must be judged by a knowledgeable caregiver. Recent experience also suggests that the advisability to personalize care also applies to other aspects of ARDS management, such as prone positioning and paralytics. ${ }^{17,18}$ At the bedside, published tables are not enough; physiological observations with a strong scientific rationale serve as a better guide to intervention. Like all powerful drugs with benefits and side effects, PEEP applied to critically ill patients with ARDS must be dosed carefully.

\section{David J Dries John J Marini \\ Regions Hospital, University of Minnesota Minneapolis/St. Paul Minnesota}

\section{REFERENCES}

1. Ashbaugh DG, Bigelow DB, Petty TL, Levine BE. Acute respiratory distress in adults. Lancet 1967;2(7511):319-323.

2. Suter PM, Fairley B, Isenberg MD. Optimum end-expiratory airway pressure in patients with acute pulmonary failure. $\mathrm{N}$ Engl $\mathrm{J}$ Med 1975;292(6):284-289.

3. Suter PM, Fairley HB, Isenberg MD. Effect of tidal volume and positive end-expiratory pressure on compliance during mechanical ventilation. Chest 1978;73(2):158-162.

4. Slutsky AS, Ranieri VM. Ventilator-induced lung injury. N Engl J Med 2013;369(22):2126-2136.

5. ARDS Network, Brower RG, Matthay MA, Morris A, Schoenfeld D, Thompson BT, Wheeler A. Ventilation with lower tidal volumes as compared with traditional tidal volumes for acute lung injury and the acute respiratory distress syndrome. N Engl J Med 2000;342(18): 1301-1308.

6. Amato MB, Meade MO, Slutsky AS, Brochard L, Costa EL, Schoenfeld DA, et al. Driving pressure and survival in the acute respiratory distress syndrome. N Engl J Med 2015;372(8):747755.

7. Aoyama H, Pettenuzzo T, Aoyama K, Pinto R, Englesakis M, Fan E. Association of driving pressure with mortality among ventilated patients with acute respiratory distress syndrome: a systematic review and meta-analysis. Crit Care Med 2018;46(2):300-306. 


\section{EDITORIAL}

8. Gattinoni L, Marini JJ, Pesenti A, Quintel M, Mancebo J, Brochard L. The "baby lung" became an adult. Intensive Care Med 2016;42 (5):663-673.

9. Marini JJ, Rocco PRM, Gattinoni L. Static and dynamic contributors to ventilator-induced lung injury in clinical practice: pressure, energy, and power. Am J Respir Crit Care Med 2020;201(7):767-774.

10. Marini JJ, Gattinoni L. Energetics and the root mechanical cause for ventilator-induced lung injury. Anesthesiology 2018;128(6):1062-1064.

11. Brower RG, Lanken PN, MacIntyre N, Matthay MA, Morris A, Ancukiewicz M, et al. Higher versus lower positive end-expiratory pressures in patients with the acute respiratory distress syndrome. $\mathrm{N}$ Engl J Med 2004;351(4):327-336.

12. Tokics L, Hedenstierna G, Strandberg A, Brismar B, Lundquist H. Lung collapse and gas exchange during general anesthesia: effects of spontaneous breathing, muscle paralysis, and positive end-expiratory pressure. Anesthesiology 1987;66(2):157-167.

13. Sahetya A, Hager D, Stephens R, et al. Positive end-expiratory pressure titration to minimize driving pressure in patients with the acute respiratory distress syndrome: a prospective physiological study. Resp Care 2020;65(5):583-589.
14. ARDS Definition Task Force, Ranieri VM, Rubenfeld GD, Thompson BT, Ferguson ND, Caldwell E, et al. Acute respiratory distress syndrome: the Berlin definition. JAMA 2012;307(23):2526-2533.

15. Writing Group for the Alveolar Recruitment for Acute Respiratory Distress Syndrome Trial (ART) Investigators, Cavalcanti AB, Suzumura ÉA, Laranjeira LN, Paisani DM, Damiani LP, et al. Effect of lung recruitment and titrated positive end-expiratory pressure (PEEP) vs low PEEP on mortality in patients with acute respiratory distress syndrome: a randomized clinical trial. JAMA 2017;318(14): 1335-1345.

16. Fumagalli J, Berra L, Zhang C, Pirrone M, Santiago RRS, Gomes S, et al. Transpulmonary pressure describes lung morphology during decremental positive end-expiratory pressure trials in obesity. Crit Care Med 2017;45(8):1374-1381.

17. Gattinoni L, Taccone P, Carlesso E, Marini JJ. Prone position in acute respiratory distress syndrome: rationale, indications, and limits. Am J Respir Crit Care Med 2013;188(11):1286-1293.

18. National Heart, Lung, and Blood Institute PETAL Clinical Trials Network, Moss M, Huang DT, Brower RG, Ferguson ND, Ginde AA, et al. Early neuromuscular blockade in the acute respiratory distress syndrome. N Engl J Med 2019;380:1997-2008. 